Tjalling C. Koopmans Research Institute Thlligh Aoopman

Discussion Paper Series nr: 11-07

\title{
Labour market effects of unemployment accounts: insights from behavioural economics
}

Thomas van Huizen Janneke Plantenga 


\title{
Tjalling C. Koopmans Research Institute Utrecht School of Economics \\ Utrecht University
}

Janskerkhof 12

3512 BL Utrecht

The Netherlands

telephone $\quad+31302539800$

fax +31302537373

website www.koopmansinstitute.uu.nl

The Tjalling C. Koopmans Institute is the research institute and research school of Utrecht School of Economics.

It was founded in 2003, and named after Professor Tjalling C. Koopmans, Dutch-born Nobel Prize laureate in economics of 1975.

In the discussion papers series the Koopmans Institute publishes results of ongoing research for early dissemination of research results, and to enhance discussion with colleagues.

Please send any comments and suggestions on the Koopmans institute, or this series to J.M.vanDort@uu.nl

ontwerp voorblad: WRIK Utrecht

\author{
How to reach the authors \\ Please direct all correspondence to the first author. \\ Thomas van Huizen \\ Janneke Plantenga \\ Utrecht University \\ Utrecht School of Economics \\ Janskerkhof 12 \\ 3512 BL Utrecht \\ The Netherlands. \\ E-mail: T.M.vanHuizen@uu.nl \\ E-mail: J.Plantenga@uu.nl
}

This paper can be downloaded at: http://

www.uu.nl/rebo/economie/discussionpapers 


\title{
Labour market effects of unemployment accounts: insights from behavioural economics
}

\author{
Thomas van Huizen \\ Janneke Plantenga
}

Utrecht School of Economics Utrecht University

March 2011

\begin{abstract}
This paper reconsiders the behavioural effects of replacing the existing unemployment insurance system with unemployment accounts (UAs). Under this alternative system, workers are required to save a fraction of their wage in special accounts whereas the unemployed are allowed to withdraw savings from these accounts. Previous studies argued that such a reform will improve employment incentives considerably and thereby lead to a dramatic decrease in unemployment levels and durations. We show that this expected impact hinges critically on the assumptions on intertemporal choice. Using recent insights from behavioural economics, we demonstrate that the theoretical impact of UAs on unemployment is limited. This study points out that the overall effect of introducing an UA system on labour market behaviour is ambiguous rather than substantially positive.
\end{abstract}

Keywords: unemployment insurance; unemployment accounts; time preferences; behavioural economics

JEL classification: D03; J64; J65

\section{Acknowledgements}

The authors would like to thank Thomas Dohmen, Ivy Koopmans and Daniel Possenriede for helpful comments and suggestions. This study is part of the research programme 'Life course, social security and the labour market' at Utrecht University. Financial support from Stichting Instituut Gak is gratefully acknowledged. 


\section{Introduction}

In this paper we focus on the behavioural effects of moving from an unemployment insurance (UI) system to a system based on unemployment accounts (UAs). Under this alternative system, instead of paying UI premiums, workers are required to make monthly contributions to special individual savings accounts. While unemployed, individuals will not receive unemployment benefits but are allowed to withdraw savings from these individual accounts. At the end of the working life, the accumulated savings become (partly) accessible and thereby top up pensions. Basically, the reform replaces unemployment insurance by self-insurance through mandatory savings. However, the new scheme can provide the same level of income support to the unemployed as under the current system by allowing individuals to have a negative account balance and by nullifying debt at the end of the working life via interpersonal redistribution.

The main rationale to introduce UAs is that they could improve employment incentives considerably: because individuals withdraw their own savings to finance unemployment, they internalise the costs of unemployment and for that reason exert more effort to avoid unemployment and shorten unemployment spells. Proponents of UAs argue that this reform will reduce moral hazard and lead to a substantial drop in unemployment levels and durations (e.g. Orszag and Snower, 1999; Feldstein and Altman, 2007; Snower et al., 2009). For example, Brown et al. (2008) find that introducing an UA system could decrease unemployment levels in Europe's highunemployment countries by around 30 to 50 percent. It should be stressed that these results are obtained without reducing the level of income protection for the unemployed. As Snower et al. (2009, p.150) argue: "the resulting incentive effects of a shift to unemployment accounts can lead to substantial increases in employment rates, without making the unemployed worse off than they were under the unemployment benefits system and allowing all others who cannot finance their welfare needs out of their own accounts to receive support on the same terms and conditions as under the current system".

The trade-off between insurance and incentives is central in the literature on optimal unemployment insurance (e.g. Baily, 1978; Hopenhayn and Nicolini, 1997; Shimer 
and Werning, 2008). By improving incentives and maintaining income protection, these proposals thus overcome this trade-off. It is therefore not surprising that proposals for UAs are discussed in many countries. ${ }^{1}$

By assessing the impact of this reform option on labour market behaviour, we examine whether it can be expected that the UA system will redeem its main promise of significantly reducing moral hazard and unemployment. It is striking that most studies on UAs do not examine behavioural effects but rather assume these to be substantial and positive (e.g. Feldstein and Altman, 2007). The exception is the study of Brown et al. (2008), whose simulation results indicate large positive incentive effects (as discussed above). We argue that these results are to a large extent inflated. The main contribution of this study is to point out that the behavioural effects of UAs depend crucially on the assumption about individual time preferences. Previous studies have simplified this critical assumption. Using recent insights from behavioural economics, we demonstrate that the positive effects are expected to be limited under plausible assumptions on time preferences. In fact, the overall behavioural effects of UAs may not be positive.

The remainder of the paper is structured as follows. Section 2 reviews the literature on unemployment insurance savings accounts and illustrates that effectiveness of UAs in terms of improving labour market behaviour hinges critically on the assumptions on time preferences. In section 3 we assess the behavioural impact of the UA system. We conclude with several implications for unemployment insurance systems.

\section{Unemployment accounts: an overview of the issues}

\subsection{Proposals}

In some countries savings accounts have already been implemented in the system of social security ${ }^{2}$ and in many others this reform option is discussed ${ }^{1}$. Both

\footnotetext{
1 Proposals have been made, for instance, for the US (Kletzer and Rosen,, 2006; Kling, 2006), Germany (Boss et al., 2008), the Netherlands (Van Ours, 2003) and Denmark (Sorensen et al., 2006).

${ }^{2}$ A comprehensive savings scheme for social security exists in Singapore (Asher and Nandy, 2008): however, these are not used for unemployment. Since 2002, unemployment is financed through unemployment accounts in Chile (Acevedo et al., 2006; Sehnbruch, 2006). As the Chilean
} 
comprehensive reforms of the social security system based on individual savings accounts and savings schemes exclusively for unemployment have been proposed by several authors. ${ }^{3}$ Here we focus on the latter. As many other papers on UAs (e.g. Brown et al., 2008; Feldstein and Altman, 2007; Snower et al., 2009) we take the central features of the current UI system (benefits levels, maximum duration, profile over time, eligibility criteria etc.) as given. The focus is therefore not on the potential (behavioural) effects of reducing the level of income protection, which is maintained, but rather on the impact of reorganising the existing UI benefit schemes through the introduction of mandatory savings accounts.

Although there are differences between the various proposals, most of them have several features in common. Firstly, individuals make mandatory contributions to individual savings accounts instead of paying premiums and taxes to finance unemployment insurance. Individuals are allowed to contribute more to the accounts than the minimum rate and employers are encouraged or required to make additional contributions. In addition, an option could be to specify an UA ceiling (see for instance Feldstein and Altman, 2007). Secondly, when individuals would be eligible for unemployment benefits, they are allowed to withdraw an amount of savings from their UAs up to the level of the current unemployment insurance benefits. These withdrawals thereby replace the existing insurance benefits. However, unemployed individuals can opt for lower 'benefits' than the maximum withdrawal levels. Thirdly, UAs are (either explicitly or implicitly) integrated in pension schemes as the accumulated savings become available at the retirement age. Fourthly, the unemployment insurance savings accounts include two insurance elements: these are essential in order to provide the same level of income protection as the current UI system. The scheme provides liquidity insurance by allowing individuals to have a negative account balance. So, even when individuals have not accumulated sufficient savings to finance unemployment, income support can still be provided through this

unemployment scheme differs significantly from the UA proposals on which we focus, we do not discuss the Chilean case in detail.

${ }^{3}$ See for proposals of comprehensive social security reforms: Orszag and Snower (1999); Fölster (2001); Snower et al., 2009. Others focus on savings accounts for unemployment (e.g. Feldstein and Altman, 2007; Orszag and Snower, 2002; Stiglitz and Yun, 2005. See Bovenberg et al. (2008) for a review of the pros and cons of various policy options. 
credit facility. In addition, the system provides a form of lifetime income insurance: individuals who enter retirement with a negative account balance will still be entitled to basic retirement benefits as the debt on the UA will be cancelled by the government. ${ }^{4}$ So, unemployment accounts allow for intrapersonal redistribution as well as interpersonal redistribution.

\subsection{Assessments}

The previous studies on savings schemes for unemployment examine the following issues: theoretical welfare implications; the viability of UAs and the effects on lifetime income distribution; and the impact on employment incentives and labour market behaviour. Bovenberg and Sorensen (2004), Jongen (2009) and Stiglitz and Yun (2005) focus on the first of these issues. Bovenberg and Sorensen (2004) find that replacing the UI system by an UA system leads to a (substantial) Pareto improvement because both liquidity insurance and lifetime income insurance will be provided more efficiently. Conversely, Jongen (2009) shows that the welfare gains of introducing UAs may be rather small. Stiglitz and Yun (2005) point out that replacing unemployment benefits by individual savings is more likely to enhance welfare when risk aversion is lower, search elasticity is higher and the unemployment risk is lower.

A major part of the previous literature deals with the viability of the reform and analyses its impact on lifetime income distribution. In general, these studies make use of empirical data and apply simulation techniques. A central question is whether the unemployment accounts can finance a substantial part of the unemployment payments. If unemployment is concentrated in a rather small group of the population, the unemployed would typically have exhausted account balances and, since UA debt is cancelled at retirement, they would have to rely on interpersonal redistribution. Unemployed individuals would then face the same adverse incentive effects as under the current system. Feldstein and Altman (2007) make use of US panel data (PSID) to address this issue. Simulating the effects of the UAs system, they indicate that almost all individuals (between 93 and 94.8 percent) will have positive balances at retirement: "the evidence that most individuals have positive balance accounts and

\footnotetext{
${ }^{4}$ This form of interpersonal redistribution can for instance be financed through taxing the account balances (see for instance Snower et al., 2009).
} 
that they end their career with positive balance accounts shows that (assuming they understand this likelihood) they generally face the cost of unemployment and would have little incentive for behaviour that would increase either the frequency or duration of unemployment" (Feldstein and Altman, 2007, p.48). However, the empirical analysis indicates that the shift from the UI system to an unemployment accounts system has (small) adverse redistributive effects.

Vodopivec and Rejec (2001) and Vodopivec (2010) performed similar analyses for respectively Estonia and Slovenia and, compared to Feldstein and Altman, found a higher share of the population that would experience a negative balance during the life course and end the working life with a UA debt. Moreover, both studies indicate that the reform may have substantial (adverse) effects on the lifetime income distribution. Fölster (2001) and Fölster et al. (2002), using Swedish data, and Sorensen et al. (2006), making use of Danish data, examine the viability of a more comprehensive savings accounts based reform. The results indicate that the reform could increase the inequality of lifetime income.

The aforementioned studies do not examine the impact of UAs on employment incentives and labour market behaviour. Feldstein and Altman (2007) for example perform several simulations, ignoring behavioural responses in most simulations and assuming a 10 or 30 percent decrease in unemployment duration in some simulations. They present evidence that almost all workers will have a positive account balance at retirement which "suggests a substantial improvement in the incentives of the unemployed" (Feldstein and Altman, 2007, p.56). Sorensen et al. (2006) examine behavioural changes; however, these are static "aggregate back-of-the-envelope calculations" (p.31). As improving incentives is the main rationale to introduce an UA system, behavioural effects are generally assumed to be positive and significant. Consequently, most papers focus on the potential obstacles by examining the viability of UAs and the potential adverse redistributive effects.

An exception is the study of Brown et al. (2008). Their theoretical analysis shows that UA will increase the reward for keeping and seeking a job through two effects. First, an internalisation effect implies that individuals stand to loose more from being unemployed because they have to finance their unemployment with their own savings. 
Second, there is a tax reduction effect because a part of the unemployed individuals finance their own unemployment, thereby not imposing costs on others. This leads to lower taxes which in turn increases the rewards for seeking and keeping a job. Moreover, there is an indirect tax reduction effect: the increase in employment broadens the tax base and thereby results in lower taxes, which again improves employment incentives. Using data from several European countries, they calibrate this model and demonstrate that introducing unemployment savings accounts will have substantial effects on unemployment: the predicted drop in unemployment rates varies from 34.4 percent in Italy to 50.9 percent in Germany. However, they note that "our models of course make strong simplifying assumptions and thus our results must be interpreted with caution, indicating only general orders of magnitude" (Brown et al., 2008, p.599).

\subsection{Assumptions}

In order to assess the behavioural impact of the introduction of UAs, we should examine under which conditions the incentives provided by the UA system are effective. Given that the level and potential duration of income support, as well as the eligibility criteria remain unchanged, what exactly are these incentives? When a worker becomes unemployed, he withdraws from his individual account an amount of savings. As the accumulated UA savings become available at retirement age, a longer duration of unemployment spells and a higher frequency of unemployment during the life course imply a reduction of his UA wealth. Thus, the unemployment accounts system provides an incentive to avoid unemployment through a 'retirement bonus' (or, as termed by Snower et al. (2009), 'pension top-up').

There are therefore two critical assumptions. First of all, the effectiveness of this incentive depends crucially on whether individuals expect that they will end their working life with a positive UA balance. Because UA debt is nullified at retirement, the incentives for people who expect to have a negative terminal account balance will be the same as under the current UI system. On the other hand, individuals who expect to enter retirement with a positive UA balance will have an incentive to keep and seek a job. 
As discussed above, this issue is addressed in several studies. For instance, Feldstein and Altman (2007) show that it is likely that a rather small proportion of the individuals would end their working life with a negative balance and therefore argue that the reform improves the incentives for a large majority of the population. However, demonstrating that most individuals will have a positive terminal balance ex post, does not imply that they expect this outcome ex ante. Nevertheless, it can be argued that by exerting more effort to keep and seek a job, workers can affect both the probability that the terminal account will be positive and, given a positive balance, the level of the pension top-up. Hence, the incentive produced by UAs exists for all individuals attaching a positive probability to this outcome.

Second of all, even if a large part of the population expects to receive an UA retirement bonus, whether this incentive effectively alters behaviour depends on how individuals value this future payoff. Will the self-insurance or internalisation effect lead to a substantial increase in work and search effort? To assess the impact of the UA system, a fundamental question therefore is how the additional future reward for keeping and seeking a job is valued. How does the UA retirement bonus affect intertemporal choice?

In the next section we examine the behavioural effects of replacing the existing UI system by UAs. First, we discuss the impact according to the standard economic model of intertemporal choice (3.1): it can be demonstrated that both the level of and variation in discount rates matter for the effectiveness of the savings scheme. Next, we consider the limitations of the standard model (3.2) and examine the impact of the proposed reform under an alternative model of time preferences (3.3). Finally, we show that when workers approach the retirement age, an additional effect kicks in besides the effects on search and work effort (3.4).

\section{Behavioural impact of Unemployment Accounts}

\subsection{Effects of UAs under exponential discounting}

The exponential discounting model is the standard economic model of intertemporal choice. In general it is assumed that individuals have well-defined preferences and try 
to maximize life-time utility according to (a variant of) the following intertemporal utility function:

$U^{t}\left(u_{t}, u_{t+1}, \ldots, u_{T}\right)=\sum_{\tau=t}^{T} \delta^{t} u_{t}$

where $t$ denotes the time period, $u_{t}$ represents the instantaneous utility in period $\mathrm{t}$ and $\delta$ is the discount factor $(0<\delta \leq 1)$, indicating the individual's time preference. ${ }^{5}$ Workers with a higher discount factor (i.e. lower discount rate) care more about the future and can thus be considered more 'patient'

Moving from an UI system to an UA system will affect the future streams of utilities through rewarding individuals with a pension top-up for keeping and seeking a job. As Brown et al. (2008) perform the most comprehensive analysis of the incentive and behavioural effects of UAs, their study provides a useful benchmark. Their theoretical model is based on the work of Phelps (1994) and consists of two periods. The period of analysis is one year and the annual discount rate is assumed to equal to the annual discount rate, which is set at 4 percent. $^{6}$ The main incentive effect - the internalisation effect - arises when the individual was employed in the first period. In that case, the reward for keeping a job in the second period is equal to the difference between the net wage and the level of unemployment benefits under the existing UI system, but will be equal to the entire net wage under the UA system. ${ }^{7}$ Basically, if the individual was employed in the first period he has accumulated UA savings and therefore fully finances his own unemployment in the second period. The agent thus completely internalises the costs of unemployment. Brown et al. (2008, p.594) state that their analysis demonstrates that "for reasonable parameter values, the unemployment

\footnotetext{
${ }^{5}$ The discount factor is negatively related to the discount rate: $\delta=\frac{1}{(1+r)^{t}}$
}

Where $\mathrm{r}$ is the discount rate, which is discretely compounded over time $\mathrm{t}$.

${ }^{6}$ The interest rate is set at 4 percent as this is the average interest rate in the OECD countries over the last four decades.

${ }^{7}$ The reward for keeping a job equals $\Delta_{n}^{A}=w(1-\tau)-b$ under the UI system and $\Delta_{n}^{A}=w(1-\kappa)$ under the UA system ( $w$ is the wage, $b$ unemployment benefits, $\tau$ taxes under the UI system and $\kappa$ taxes under the UA system). In addition to the internalization effect, there is a tax reduction effect if $\kappa<\tau$ (see section 2.2). However, such effects are indirect as they depend on the internalisation effect on unemployment. 
reductions can be substantial in Europe's high-unemployment countries". Can these parameters indeed considered reasonable?

In a (two period) model where the discount rate is set equal to the interest rate, the critical role of time preferences is assumed away. When a worker expects to have a positive UA balance at retirement and would withdraw savings or 'benefits' $b$ per month during unemployment, being (longer) unemployed implies an expected decrease of the pension top-up by $b$ plus interest. When the interest rate equals the discount rate, this loss has a net present value of $b$, independent of the distance to retirement. ${ }^{8}$ Hence, in this scenario individuals care the same about losing money from their UA as they care about losing cash-on-hand or money in their normal bank account.

Even under exponential discounting these assumptions on time preferences seem unrealistic. Two main points of criticism can be formulated. Firstly, there is no reason to set the discount rate equal to the interest rate. Although an average discount rate of 4 percent is within the range of the estimates of some studies, it is rather low according the large majority of the findings collected in the past decades (e.g. Frederick et al., 2002). If we no longer assume that the interest and discount rate are identical, but instead rely on empirical estimates of the discount rate, the present value of UA pension top-ups may be (substantially) lower. As estimated discount rates vary considerably between studies, it is impossible to infer the 'real' level of the discount rate. For example, Dohmen et al. (2010) find a median discount rate between 27.5 and 30 , using data which is randomly drawn from the German population. This level is comparable to discount rates found in other studies (e.g. Andersen et al., 2010; Harrison et al., 2002; Warner and Pleeter, 2001). Setting the discount rate at this level, mid-career individuals will hardly take into account the level of pension top-ups. For these individuals, the magnitude of the additional incentive provided by UAs compared to the current UI system would be less than 0.5 percent of benefits $b$ per

${ }^{8} \delta^{N}(1+r)^{N} b=b$ when $\delta=\frac{1}{(1+r)}$. 
additional month of unemployment. ${ }^{9}$ It is thus unlikely that the reform has substantial effects on unemployment for these workers. ${ }^{10}$ Obviously, the effect depends to a large extent on the age of the individual: older workers may be more sensitive to the retirement bonus, but younger workers are even less affected. The bottom line is that when the discount rate is set at a plausible level and the distance to retirement is sufficiently large, the behavioural effects of the potential reform evaporate to a large extent.

A second point of criticism is that not only the median or average discount rate but also the variation between individuals matters. Several studies indicate substantial heterogeneity in discount rates between individuals (e.g. Andersen et al., 2010; Harrison et al., 2002). For instance, the results of Dohmen et al. (2010) indicate that about 12 of the sample has a discount rate below 5 (which is broadly in the range of the discount rate set by Brown et al. (2009)), whereas almost a quarter has a discount rate over 52.5. The level of the UA pension top-up matters more for the former, patient group, whereas the latter, myopic group hardly takes this (distant) future bonus into account. In general, the behavioural effects of an UA system will be larger for the more patient individuals.

\footnotetext{
${ }^{9}$ For instance, when the retirement age is 65 , a 40 -year old individual has to wait another 25 years to access (part) of his UA savings. Given a median discount rate of 28.75 (between 27.5 and 30), the net present value of $b$ will be:

$\left(\frac{1}{(1+0.2875)}\right)^{25}(1+0.04)^{25} b=0.00481 b$

Less than 5 percent of unemployment benefits. To exemplify, if $b$ equals 1500 euro per month, being unemployed for an additional month implies that the resulting decrease in the pension top-up has a net present value of 7.22 euro. Note that this should be interpreted as the upper bound of the effect: such an effect holds when workers are certain that they enter retirement with a positive account balance and when the UA pension top-up will not be taxed. In fact, for most workers it is uncertain that they will have a terminal UA balance. Moreover, the terminal balance may be taxed, so workers may receive only a part of their UA savings (Snower et al., 2009). Under both conditions, the effect will be smaller. ${ }^{10}$ A similar decrease in the unemployment levels would, even under a elasticity of 1 (which is high considering the empirical evidence: see Holmlund, 1998; Krueger and Meyer, 2002), lead to a less than a 0.5 percent decrease in unemployment.
} 
Heterogeneity in discount rates is highly relevant for the effectiveness of UAs because individuals with a relatively high unemployment risk - those who are young, low educated and have a lower income - have a higher discount rate (Andersen et al., 2010; Becker and Mulligan, 1997; Dohmen et al., 2010; Harrison et al., 2002; Warner and Pleeter, 2001). Thus, impatient individuals (those who are on the right side of the discount rate distribution), the group which is generally the most vulnerable to the unemployment risk, will hardly internalise the distant future reward for keeping and seeking a job and will therefore be the least affected by the potential reform. Encouraging those individuals to avoid unemployment, who will spend no or little time in the state of unemployment, is unlikely to affect unemployment significantly. Hence, UAs seem ill-targeted.

\subsection{An alternative model: hyperbolic discounting}

Although the exponential discounting model has been and still is the standard model of intertemporal choice in economics, its descriptive validity has been challenged by many scholars. As stated by Frederick et al. (2002, p.393), the exponential discounting model "which continues to be widely used by economists, has little empirical support...Indeed, virtually every core and ancillary assumption of the [exponential discounting] model has been called into question by empirical evidence collected in the past two decades". One assumption in particular has been criticized: exponential discounting implies that individuals have time-consistent preferences, which means that "[a] person feels the same about a given trade-off no matter when she is asked" (Rabin, 1998). Basically, the preference for A at some future time ' $t$ ' over $B$ at time ' $t+x$ ', implies a preference for A over B for all values of $t$.

Yet, common sense and experimental evidence suggest that preferences are timeinconsistent. As Thaler (1981) argues, some people may prefer one apple today to two apples tomorrow, but no one prefers 'one apple in one year' to 'two apples in one year plus one day'. If the discount rate is constant, which is the case in exponential discounting models, both choices are (formally) identical. People have timeinconsistent preferences if they initially opt for the 'two apples in one year plus one day' option, but prefer 'one apple today' when a year has passed. Evidence from a wide range of laboratory experiments (see Frederick et al., 2002) supports the perspective that individual time preferences are dynamically inconsistent. Particularly, 
experiments point out that the discount rate is a decreasing function of time: discounting is steeper in the immediate future than in the more distant future. For instance, Thaler (1981) found that the median subject is indifferent between $\$ 15$ today and $\$ 20$ in one month and between $\$ 15$ today and \$100 in ten years. The former implies an annual discount rate of over 300 percent, while the latter implies an annual discount rate of about 19 percent.

In order to incorporate time-inconsistent preferences (and other anomalies of the standard model), several alternative models have been proposed, varying from hyperbolic discounting models, to dual-self models (Fudenberg and Levine, 2006; Thaler and Shefrin, 1981) and models of temptation (Gul and Pesendorfer, 2001). Here we focus on (quasi-)hyperbolic discounting models because these types of models have been examined in most of the applied research and, as we will demonstrate in the next section, can be used to derive predictions on labour market behaviour. Based on the work of Strotz (1956) and Phelps and Pollak (1968), Laibson (1997) proposes the following quasi-hyperbolic discounting model (hyperbolic discounting models hereafter):

$$
U^{t}\left(u_{t}, u_{t+1}, \ldots, u_{T}\right)=u_{t}+\beta \sum_{\tau=t+1}^{T} \delta^{t} u_{t}
$$

The difference between the exponential discounting model and this model is the introduction of the $\beta$ parameter $(0<\beta \leq 1)$, which indicates a preference for immediate gratification. When $\beta$ is equal to one, the model is identical to the standard exponential model. However, when this parameter is below one, the individual's preferences are present-biased: such a model captures the idea of time-inconsistent preferences.

An important implication of this type of models is that individuals have self-control problems. "We would 'like' to behave in one manner, but instead we 'choose' to behave in another. In particular, we tend to pursue immediate gratification in a way that we ourselves do not appreciate in the long run" (O'Donoghue and Rabin, 2000, p. 233). Although individuals may be unwilling to engage in an investment activity (which involves immediate costs and delayed rewards) in the present or near future, they may be willing and planning to do so in the more distant future. However, as time passes and the future becomes the present, the person prefers to abandon the 
original plan and tends to procrastinate. In the end, people end up continuing to postpone the activity until the next period.

In the literature on hyperbolic discounting models, the assumptions concerning an individual's beliefs about future behaviour and self-control problems play an important role. Strotz (1956) discusses two distinct cases: 'sophisticates' predict their future behaviour in the correct way and are fully aware of their self-control problems $(\widehat{\beta}=\beta)$, whereas 'naives' believe they will behave as planned and are completely unaware of their self-control problems $(\widehat{\beta}=1)$. O'Donoghue and Rabin (2001) argue that both cases may be too extreme and therefore develop a model of partial naiveté, in which individuals are aware of their self-control problems, but underestimate the degree $(\beta<\widehat{\beta}<1)$. An important implication is that (partially) sophisticated people know they will have self-control problems in the future and are willing to constrain future choices, even if this involves costs. Mechanisms or instruments which restrict the possibilities of 'future selves' to pursue immediate gratification - labelled as commitment devices in the behavioural economics literature - are valued by (partly) sophisticated agents as such instruments can raise their long-run welfare (e.g. Strotz, 1956; Laibson, 1997). ${ }^{11}$

In addition to evidence from numerous experimental studies, findings from field data provide support for the hyperbolic discounting model: findings on saving and consumption behaviour, exercise, homework, deadlines, the impact of default options and effectiveness of commitment devices are hard to reconcile with standard economic theory but can be explained by hyperbolic discounting models (see DellaVigna (2009) for a recent review on field evidence).

\subsection{Effects of UAs under hyperbolic discounting}

Given the empirical support for the hyperbolic discounting model, a critical question is how labour market behaviour will be affected by unemployment accounts if

\footnotetext{
${ }^{11}$ See Thaler and Benartzi (2004) and Ashraf et al. (2006) for real world examples of commitment devices.
} 
hyperbolic time preferences are assumed. And, is job search behaviour consistent with the exponential or hyperbolic discounting model?

DellaVigna and Paserman (2005; DV\&P hereafter) developed a job search model that incorporates hyperbolic discounting and leads to several theoretical predictions on the relation between discounting and job search behaviour. Firstly, they demonstrate that job search intensity is positively related to both $\delta$ and $\beta$. The choice on search effort is principally an investment decision involving immediate costs - looking for job openings, contacting employers, going to job interviews - and future rewards in terms of better job opportunities. For that reason search effort increases with the individual's degree of patience.

Secondly, $\delta$ is positively related to reservation wages: the more patient (higher $\delta$ ) the job seeker, the more he is inclined to reject the offer and search for better jobs. Conversely, the reservation wage is orthogonal to $\beta$ for naïve hyperbolic workers. The intuition is that the reservation wage decision involves comparing delayed payoff streams: accept a job and receive the offered wage in the future or reject the offer and wait for a better job. As immediate payoffs are not affected, this is not directly dependent on $\beta$. However, for sophisticated hyperbolic individuals there is an indirect (and relatively small) effect of $\beta$ on reservation wages through expectations.

Finally, the effect of patience on the exit rate depends on the joint impact of patience on search intensity and reservation wages. The exit rate consists of the probability of finding a job offer times the probability that this offer is accepted. For naïve workers, the effect of $\beta$ is unambiguous: the level of search effort increases with $\beta$, while the effect on the reservation wage is absent. Hence, for naïve hyperbolic agents patience has a positive impact on the exit rate. Both $\delta$ and $\beta$ (under sophistication) are positively related to job search intensity and the reservation wage: the former implies an increase in the exit rate, whereas the latter implies a decrease in the exit rate to employment. DV\&P demonstrate that for sophisticated agents the search intensity effect dominates and $\beta$ is positively related with the exit rate. Conversely, under exponential discounting, the reservation wage effect dominates and $\delta$ has a negative effect on exit rates. "In a nutshell, due to different time horizons, variation in $\delta$ 
primarily drives variation in reservation wages while variation in $\beta$ primarily drives variation in search effort" (DV \&P, 2005, p.544).

DV\&P test these predictions using two US longitudinal data sets (NLSY and PSID). The study examines the effects of patience on search effort, (self-reported) reservation wages and the duration of unemployment. Although in principle their measure of patience could capture variation in $\beta$ or in $\delta$ (or both), the empirical results seem to be driven by variation in $\beta$ : the patience measure is orthogonal to the reservation wage but positively related to job search intensity and the exit rate. These findings thus provide support for the hyperbolic discounting model. Ben Halima and Ben Halima (2009) replicate the findings of DV\&P for France. Moreover, empirical evidence indicates that on-the-job behaviour (i.e. high levels of work effort, on-the-job search) of employees is also compatible with the hyperbolic discounting model (Drago, 2006). The results show that patience is positively related to 'on-the-job collaboration' or work effort, and negatively related to job-job transitions.

The finding that job search behaviour is in line with the hyperbolic discounting model implies that in general job seekers have a tendency to procrastinate job search activities. This is consistent with evidence from time-use studies that the unemployed spend a small amount of time on job search activities. For example, Barron and Mellow (1979) find that job seekers spend on average 7 hours a week on job search. In addition, Krueger and Mueller (2008) show that US and Western European unemployed individuals devote on average respectively 32 and 11 minutes per day on job search activities.

So, taking into account this empirical evidence, what are the expected effects of introducing an UA system? This reform affects the payoff structure of two decisions. Firstly, the search intensity decision is mainly influenced by (immediate) short-term costs and benefits. Hyperbolic job searchers have a tendency to procrastinate job search activities and distant future incentives do not provide an effective instrument to overcome these procrastination problems. Since UAs provide a distant future incentive to increase job search effort, it is unlikely that the reform increases search intensity significantly. Secondly, the job acceptance decision is based on the evaluation of different future income streams, and therefore it can be expected that the 
reform influences this decision. However, the effect on unemployment duration is probably rather small because short-term payoffs are relatively more important than long-term payoffs, and the 'costs' of unemployment may be rather small compared to the total lifetime income. Moreover, empirical evidence indicates that the unemployment duration is much less affected by the reservation wage than by the job arrival rate. In fact, most job offers are accepted (Devine and Kiefer, 1991; Eckstein and Van den Berg, 2007). Thus, if we assume hyperbolic discounting, providing such distant future incentives may have no significant effect on job search effort and little effect on the job acceptance decision. It can therefore be expected that the effect of UA on the level of unemployment and unemployment duration will be limited.

Again, heterogeneity in time preferences is important. As shown by DV\&P, impatient unemployed job seekers search less intensively for a job and have longer unemployment durations. Likewise, Paserman (2008) finds that low and middle income groups have a large present-bias (low $\beta) .{ }^{12}$ Furthermore, impatient workers exert lower levels of work effort. The behaviour of impatient, present-biased individuals will be hardly affected by the introduction of UAs. This has implications for the general effectiveness of the reform, because these groups have a relatively high chance of entering unemployment and have longer unemployment spells.

\subsection{Short-term incentives for pre-retirees}

The previous analyses of the effects of UAs hold when workers perceive retirement and therefore the UA pension bonus - as a distant future event. Empirical evidence shows that a large part of employees do hardly any planning for retirement and have not tried to determine how much they need to save for (a pleasant) retirement (e.g. Lusardi, 2001; Yakoboski and Dickemper, 1997). Lusardi (2001), for instance, illustrates that about one third of the Health and Retirement Study respondents have "hardly thought" about retirement. This figure is particularly striking as the

\footnotetext{
${ }^{12}$ The point estimates of $\beta$ are rather low for low and middle income groups (respectively $\beta=0.40$ and $\beta=0.48)$. For high income groups $\beta$ is relatively high $(\beta=0.89)$. Due to large standard errors, the longrun discount factor $\delta$ could not be identified. Other studies found [ $\beta=0.70, \delta=0.96]$ (Laibson et al., 2009); [ $\beta=0.34, \delta=0.88]$ (Fang and Silverman, 2007), [ $\beta=0.53, \widehat{\beta}=0.90, \delta=0.88]$ (Skiba and Tobacman, 2008).
} 
respondents are older workers who will retire within the next five to ten years. The empirical phenomenon that people procrastinate saving and planning for retirement is consistent with the hyperbolic discounting model. In fact, it is one of the main reasons to introduce mandatory retirement schemes: "The principal rationale for such mandatory programs is that some individuals lack the foresight to save for their retirement years" (Feldstein, 1985, p. 303). For the most part of the working life, retirement can be considered as an (far) distant future event. Therefore, the behavioural effects of UAs discussed above are relevant for the major part of the labour force.

Nevertheless, when workers are approaching the retirement age, the distant future incentive generated by the UA retirement bonus becomes a near future incentive. As the present value of the retirement bonus increases with the proximity to retirement, the positive effect on job search incentives becomes larger. However, at the same time a second effect kicks in. Workers who have accumulated a significant amount of savings during their working life and have not been unemployed (frequently or longterm) will be entitled to a substantial retirement bonus. ${ }^{13}$ In general, the higher the life-time income of the individual, the higher will be the UA retirement bonus. This bonus may not only affect job search incentives, but may also encourage workers to retire early. ${ }^{14}$ To finance early retirement, the older workers can use their private noncontractual savings: they do not longer need these savings during their normal retirement years as they have build up a (large) retirement nest egg through the UA system. Hyperbolic discounters have a preference for instant gratification and therefore have a tendency to retire early. As a result, the effect of this short-term incentive may be substantial. Various studies point out that a higher level of (pension) wealth induces people to retire early (Bloemen, 2008; Buetler et al., 2005; Samwick, 1998). Given that the retirement bonus increases the level of pension wealth, it is likely that the reform will encourage early retirement, particularly among higher

\footnotetext{
${ }^{13}$ This depends of course on whether there will be an UA savings ceiling, and the level of such an upper limit.

${ }^{14}$ It may be argued that workers can also use the current unemployment benefit system to retire early. It should be stressed that when a worker leaves the employer voluntarily, he would be ineligible for unemployment benefits under the current UI system and loses his accrued rights. Conversely, under the UA system the worker who leaves his job voluntarily keeps his accumulated savings.
} 
income groups. Thereby, UAs may reduce labour market participation, decrease the tax base and in this way reduce employment.

\section{Conclusion and discussion}

The main objective of unemployment insurance is to provide income protection against the risk of unemployment. However, UI involves welfare costs due to adverse incentive effects: UI reduces the incentives to search intensively for a job and to accept a job offer. Proposals to replace the unemployment insurance system by an unemployment accounts system seem particularly interesting as they promise to mitigate these moral hazard effects considerably while maintaining the level of income protection.

Previous studies that assessed the impact of this reform found that UA will enhance welfare, have (limited) adverse effects on lifetime income distribution, improve labour market incentives substantially and lead to a dramatic drop in the unemployment rate. When a policy proposal involves large gains and hardly any costs, the balance may seem obvious.

We demonstrated that the behavioural effects of UAs depend crucially on the assumptions on time preferences. As Brown et al. (2008) showed, when the population would consist entirely of patient exponential discounters, the effect of UAs on employment incentives and behaviour may be substantial and positive. However, when a more plausible level of patience is assumed, the impact of the reform may be rather small. Furthermore, if we assume hyperbolic instead of exponential discounting, the effect evaporates: relying on distant future incentives to reduce unemployment seems to be an unfruitful strategy. Under both exponential and hyperbolic discounting, UAs seem ill-targeted. To be specific, those who need to be incentivised the most - individuals with a relatively high probability to enter unemployment and a long duration of unemployment, workers who exert low work effort and unemployed individuals who not search intensively - will be the least affected by the proposed reform. Moreover, a system based on saving accounts may increase the level of pension wealth, thereby inducing early retirement. Thus, the impact of unemployment accounts on labour supply incentives is not unambiguously 
positive. Reforming the UI system through the introduction of UAs may lead to adverse redistributive effects, limited effects on unemployment levels and may stimulate early retirement. Given such effects, the balance of costs and benefits seems not clear a priori.

If hyperbolic discounting models describe human behaviour accurately, the standard (exponential) models overestimate the impact of long-run incentives. As job search is an investment activity and individuals have a tendency to procrastinate on such activities, introducing commitment devices to overcome the procrastination problem may be more effective. Intensifying monitoring of job search effort could function as such a commitment device. Recent empirical evidence shows that more stringent monitoring of job search substantially reduces the duration of unemployment (Abbring et al., 2005; Arni et al., 2009; Boockermann et al., 2009; Lalive et al., 2006; McVicar, 2008). More intensified monitoring decreases the welfare of exponential discounters, while it increases (the long-run) welfare of hyperbolic discounters (Paserman, 2008). Interestingly, monitoring job search as an instrument to mitigate moral hazard is on the rise in OECD countries (OECD, 2007).

Finally, it should be stressed that we do not claim that the hyperbolic discounting model is the only 'real' model of intertemporal choice. Some researchers argue that the population consists of both time consistent and time inconsistent agents (e.g. Meier and Sprenger, 2010), others have criticised the (hyperbolic) discounting models in general (e.g. Rubinstein, 2003). However, if we take seriously the large amount of empirical evidence on time preferences, we have to conclude that the positive employment effects assumed and estimated in previous studies are largely inflated. An important agenda for future research is therefore to examine the role of time preferences in labour market models. Specifically, the role of hyperbolic discounting in job search models deserves further attention.

\section{References}

Abbring, J.H., van den Berg, G.J. and van Ours, J.C. 2005. The effect of unemployment insurance sanctions on the transition rate from unemployment to employment, Economic Journal, vol. 115, 602-630 
Acevedo, G., Eskenazi, P. and Pages, C., 2006. Unemployment insurance in Chile: A new model of income support for unemployed workers. Social Protection Discussion Paper no. 0612, World Bank, Washington, D.C

Andersen, S., Harrison, G.W., Lau, M.I. and Rutström, E.E. 2010. Preference heterogeneity in experiments: Comparing the field and laboratory, Journal of Economic Behavior and Organization, vol. 73, no. 2, 209-224

Arni, P., Lalive, R. and van Ours, J.C. 2009. How effective are unemployment Benefit sanctions? Looking beyond unemployment exit, Discussion Paper no. 4509, IZA, Bonn

Asher, M.G. and Nandy, A. 2008. Singapore's policy responses to ageing, inequality and poverty: An assessment, International Social Security Review, vol. 61, no. $1,41-60$

Ashraf, N., Karlan, D. and Yin, W. 2006. Tying Odysseus to the mast: Evidence from a commitment savings product in the Philippines, Quarterly Journal of Economics, vol. 121, no. 2, 635-672

Baily, M.N. 1978. Some aspects of optimal unemployment insurance, Journal of Public Economics, vol. 109, no. 3, 379-402

Barron, J.M. and Mellow, W. 1979. Search effort in the labor market, Journal of Human Resources, vol. 14, no. 3, 389-404

Becker, G.S. and Mulligan, C.B. 1997. The endogenous determination of time preference, Quarterly Journal of Economics, vol. 112, no. 3, 729-758

Ben Halima, B. and Ben Halima, M.A. 2009. Time preferences and job search: Evidence from France, Labour, vol. 23, no. 3, 535-558

Bloemen, H.G. 2008. Private wealth and job exit at older age: a random effects model, Discussion Paper no. 3386, IZA, Bonn

Boockmann, B., Thomsen, S.L. and Walter, T. 2009. Intensifying the use of benefit sanctions: An effective tool to shorten welfare receipt and speed up transitions to employment?, Discussion Paper no. 4580, IZA, Bonn

Boss, A., Brown, A.J.G. and Snower, D.J. 2008. Beschäftigungskonten für Deutschland, Perspektiven der Wirtschaftspolitik, vol. 9, no. 2, 139-155

Bovenberg, A.L., Hansen, M.I. and Sørensen, P.B. 2008. Individual savings accounts for social insurance: Rationale and alternative designs, International Tax and Public Finance, vol. 15, no. 1, 67-86 
Bovenberg, A.L. and Sorensen, P.B. 2004. Improving the equity-efficiency trade-off: Mandatory savings accounts for social insurance, International Tax and Public Finance, vol. 11, no. 4, 507-529

Brown, A.J.G., Orszag, J.M. and Snower, D.J. 2006 Unemployment accounts and employment incentives, European Journal of Political Economy, vol. 24, no. $3,587-604$

Buetler, M., Huguenin, O. and Teppa, F. 2005. Why forcing people to save for retirement may backfire, Working Paper no. 1458, CESifo, Munich

DellaVigna, S. 2009. Psychology and economics: Evidence from the field, Journal of Economic Literature, vol. 47, no. 2, 315-372

DellaVigna, S. and Paserman, M.D. 2005. Job search and impatience, Journal of Labor Economics, vol. 23, no. 3, 527-588

Devine, T.J. and Kiefer, N.M. 1991. Empirical labor economics: The search approach, New York, Oxford University Press

Dohmen, T., Falk, A., Huffman, D. and Sunde, U. 2010. Are risk aversion and impatience related to cognitive ability?, American Economic Review, vol. 100, no. $3,1238-1260$

Drago, F. 2006. Career consequences of hyperbolic time preferences, Discussion Paper no. 2113, IZA, Bonn

Eckstein, Z. and van den Berg, G.J. 2007. Empirical labor search: A survey, Journal of Econometrics, vol. 136, no. 2, 531-564

Fang, H. and Silverman, D. 2007. Time-inconsistency and welfare program participation: Evidence from the NLSY, International Economic Review, vol. 50, no. $4,1043-1077$

Feldstein, M. 1985. The optimal level of social security benefits, Quarterly Journal of Economics, vol. 100, no. 2, 303-320

Feldstein, M. and Altman, D., 2007. Unemployment insurance savings accounts, pp. 35-64 in Poterba, J.M. (ed.), Tax policy and the economy Vol. 21, MIT Press, Cambridge,

Fölster, S. 2001. An evaluation of social insurance accounts, Public Finance and Management, vol. 1, no. 4, 420-448

Fölster, S., Gidehag, R., Orszag, M. and Snower, D. 2002. Assessing welfare accounts, Discussion Paper no. 533, IZA, Bonn 
Frederick, S., Loewenstein, G. and O'Donoghue, T. 2002. Time discounting and time preference: A critical review, Journal of Economic Literature, vol. 40, no. 2, $351-401$

Fudenberg, D. and Levine, D.K. 2006. A dual-self model of impulse control, American Economic Review, vol. 96, no. 5, 1449-1476

Gul, F. and Pesendorfer, W. 2001. Temptation and self-control, Econometrica, vol. 69 , no. $6,1403-1435$

Harrison, G.W., Lau, M.I. and Williams, M.B. 2002. Estimating individual discount rates in Denmark: A field experiment, American Economic Review, vol. 92, no. $5,1606-1617$

Holmlund, B. 1998. Unemployment insurance in theory and practice, Scandinavian Journal of Economics, vol. 100, no. 1, 113-141

Hopenhayn, H.A. and Nicolini, J.P. 1997. Optimal unemployment insurance, Journal of Political Economy, vol. 105, no. 2, 412-438

Jongen, E. 2009. An analysis of individual accounts for the unemployment risk in the Netherlands, Document no. 186, CPB Netherlands Bureau for Economic Policy Analysis, The Hague

Kletzer, L.G. and Rosen H.F. 2006. Reforming unemployment insurance for the twenty-first century workforce, Discussion Paper no. 2006-06, The Brookings Institution, Washington, D.C

Kling, J.R. 2006. Fundamental restructuring of unemployment insurance: wage-loss insurance and temporary earnings replacement accounts, Discussion Paper no. 2006-05, The Brookings Institution, Washington, D.C

Krueger, A.B. and Meyer, B.D. 2002. Labor supply effects of social insurance, pp. 2327-2392 in Auerbach, A.J., Feldstein, M. (eds), Handbook of Public Economics Vol. 4., Amsterdam, North-Holland

Krueger, A.B. and Mueller, A. 2008. The lot of the unemployed: A time use perspective, Discussion Paper no. 3490, IZA, Bonn

Laibson, D. 1997. Golden eggs and hyperbolic discounting, Quarterly Journal of Economics, vol. 112, no. 2, 443-477

Laibson, D., Repetto, A. and Tobacman, J. 2007. Estimating discount functions with consumption choices over the lifecycle, Working Paper no.13314, NBER, Cambridge 
Lalive, R., van Ours, J. and Zweimuller, J. 2006. How changes in financial incentives affect the duration of unemployment, Review of Economic Studies, vol. 73, no. 4, 1009-1038

Lusardi, A. (2001) Explaining why so many people do not save, Working Paper no. 2001-05, Center for Retirement Research, Chestnut Hill

Meier, S. and Sprenger, C. 2010. Present-biased preferences and credit card borrowing, American Economic Journal: Applied Economics, vol. 2, no. 1, $193-210$

McVicar, D. 2008. Job search monitoring intensity, unemployment exit and job entry: Quasi-experimental evidence from the UK, Labour Economics, vol. 15, no. 6, $1451-1468$

O'Donoghue, T. and Rabin, M., 1999. Doing it now or later, American Economic Review, vol. 89, no. 1, 103-124

O'Donoghue, T. and Rabin, M. 2000. The economics of immediate gratification. Journal of Behavioral Decision Making, vol. 13, no. 2, 233-250

O'Donoghue, T. and Rabin, M. 2001. Choice and procrastination, Quarterly Journal of Economics, vol. 116, no. 1, 121-160

OECD 2007. Employment Outlook 2007, Paris, OECD

Orszag, J.M. and Snower, D.J. 1999. Expanding the welfare system: a proposal for Reform, pp.116-135 in Buti, M., Franco D. and Pench, L. (eds), The welfare state in Europe, Cheltenham, Edward Elgar

Orszag, J.M. and Snower, D.J. 2002. From unemployment benefits to unemployment accounts, Discussion Paper no. 532, IZA, Bonn

Paserman, M.D. 2008. Job search and hyperbolic discounting: Structural estimation and policy evaluation, Economic Journal, vol. 118, 1418-1452

Phelps, E. 1994. Structural slumps: The modern equilibrium theory of unemployment, interest and assets, Cambridge, Harvard University Press

Phelps, E.S. and Pollak, R.A. 1968. On second-best national saving and gameequilibrium growth, Review of Economic Studies, vol. 35, no. 2, 185-199

Rabin, M. 1998. Psychology and economics, Journal of Economic Literature, vol. 36, no. $1,11-46$

Rubinstein, A. 2003. "Economics and psychology?" The case of hyperbolic discounting, International Economic Review, vol. 44, no. 4, 1207-1216 
Samwick, A.A. 1998. New evidence on pensions, social security, and the timing of retirement, Journal of Public Economics, vol. 70, no. 2, 207-236

Sehnbruch, K. 2006. Unemployment insurance or individual savings accounts: Can Chile's new scheme serve as a model for other developing countries?, International Social Security Review, vol. 59, no. 1, 27-48

Shimer, R. and Werning, I. 2008. Liquidity and insurance for the unemployed, American Economic Review, vol. 98, no. 5, 1922-1942

Skiba, P.M. and Tobacman, J. 2008. Payday loans, uncertainty, and discounting: Explaining patterns of borrowing, repayment, and default, Working Paper no. 08-33, Vanderbilt University Law School, Nashville

Snower, D.J., Brown, A.J.G. and Merkl, C. 2009. Globalization and the welfare state: A review of Hans-Werner Sinn's Can Germany Be Saved?, Journal of Economic Literature, vol. 47, no. 1, 136-158

Sørensen, P.B., Hansen, M.I. and Bovenberg, A. L. 2006. Individual savings accounts and the life-cycle approach to social insurance, Working Paper no. 2006-03. EPRU, Copenhagen

Stiglitz, J.E. and Yun, J. 2005. Integration of unemployment insurance with retirement insurance, Journal of Public Economics, vol. 89, no. 11-12, 2037-2067

Strotz, R.H. 1956. Myopia and inconsistency in dynamic utility maximization, Review of Economic Studies, vol. 23, no. 3, 165-180

Thaler, R.H. 1981. Some empirical evidence on dynamic inconsistency, Economic Letters, vol. 8, no. 3, 201-207

Thaler, R.H. and Benartzi, S. 2004. Save More Tomorrow: Using behavioral economics to increase employee saving, Journal of Political Economy, vol. 112, no. 1, S164-S187

Thaler, R.H. and Shefrin, H.M. 1981. An economic theory of self-control, Journal of Political Economy, vol. 89, no. 2, 392-406

Van Ours, J. 2003. WW in de 21ste eeuw, Position Paper, Ministerie van Economische Zaken, The Hague

Vodopivec, M. 2010. How viable are unemployment insurance savings accounts:

Simulation results for Slovenia, Comparative Economic Studies, vol. 52, 225247

Vodopivec, M. and Rejec, T. 2001. Unemployment insurance savings accounts:

Simulation results for Estonia, Mimeo 
Warner, J.T. and Pleeter, S. 2001. The personal discount rate: evidence form military downsizing, American Economic Review, vol. 91, no. 1, 33-53

Yakoboski, P. and Dickemper, J. 1997. Increased saving but little planning. Results of the 1997 Retirement Confidence Survey, EBRI Issue Brief, no. 191 